\title{
A Comparison between the Mechanical Behaviour of Steel Wires and Ultra High Molecular Weight Poly Ethylene Cables for Sternum Closure
}

\author{
Roelof Marissen $^{1,2}$, Mischa Nelis ${ }^{2}$, Mildred Janssens ${ }^{2}$, Michelle D. M. E. Meeks ${ }^{3}$, Jos G. Maessen ${ }^{3}$ \\ ${ }^{1}$ Faculty of Aerospace Engineering, Delft University of Technology, Delft, The Netherlands; ${ }^{2}$ DSM Dyneema, Urmond, The Nether- \\ lands; ${ }^{3}$ University Hospital Maastricht, Maastricht, The Netherlands. \\ Email: r.marissen@tudelft.nl, roelof.marissen@dsm.com
}

Received June $8^{\text {th }}$, 2011; revised June 30 ${ }^{\text {th }}$, 2011; accepted August $8^{\text {th }}, 2011$.

\begin{abstract}
Sternum closure after open heart surgery is typically done with steel wires. Final approximation of sternal parts and connection is achieved by twisting the ends of the wire and bending the twisted assembly towards the sternum in order to minimize outward protrusion. Though this routine procedure is highly effective, some failures do occur, e.g. due to wire fracture. Fatigue fracture of the wires, e.g. due to coughing implies a failure risk. An alternative development is to make cables from gel spun Ultra High Molecular Weight Poly Ethylene (UHMWPE) fibres, such fibres are extremely strong, yet flexible, and if made as a very pure grade, they are highly bio compatible. The optimal connection technique will be different from that of steel. Connection will rather be with knotting than twisting. A new sternum closure and fixation technique has been developed for the sternum. Additionally, a testing technique was developed, for a connection of simulated sternum parts, using different materials according to their respective optimal connection method and subsequently testing the mechanical properties of the connection. Substantial differences were observed. The mechanical behaviour of twisted steel wire connection showed more scatter than the knotted UHMWPE cables and some initial slack was sometimes present in the twisted cables. The maximum attainable force in the steel wires was determined by "untwisting" due to the external load. The maximum force in the UHMWPE cables was determined by the knot strength, either slipping for small knots, or breaking of the cables at the knots for slip-improved knots. The maximum force on the knotted UHMWPE cables was substantially larger than the maximum force on the twisted steel wires. Fatigue tests were performed on both the steel solution and the UHMWPE cables solution. The performance was about similar, although the simulated sternum opening was smaller for the UHMWPE cables at higher load levels. Summarizing, the UHMWPE cables show two advantages namely higher maximum load and more reproducible mechanical behaviour due to less scatter in the mechanical behaviour. On the other hand, the connection by knotting UHMWPE cables is somewhat more elaborate than the simple twisting connection of steel wires.
\end{abstract}

Keywords: Heart Surgery, Load, Displacement, Fracture, Deformation, Twisting, Knotting, Slip, Fatigue

\section{Introduction}

Open heart surgery may be inevitable if other treatments of heart disease, like angioplasty, fail. Open heart surgery requires longitudinal splitting of the sternum by median sternotomy, thus making the heart accessible for surgical treatment. The sternum has to be closed after the treatment. This is done by feeding steel wires, provided with a needle between the ribs, around both sternum halves. The needle and possible excess length is cut off and the ends are connected by twisting them together. This prac- tice is adequate in most cases. However, fracture of the wires does occur [1,2], sometimes in the surgery room, sometimes later, e.g. due to fatigue loads if patients are frequently coughing. Coughing may cause fatigue fracture of the steel wires. Metals are especially sensitive to fatigue after plastic deformation, see e.g. [3]. This is related to unfavorable residual stresses after plastic deformation and to the large amounts of dislocations in the metal crystals. The twisting of the ends implies considerable plastic deformation. Figure 1 illustrates this problem. It shows two Scanning Electron Micrographs of an 


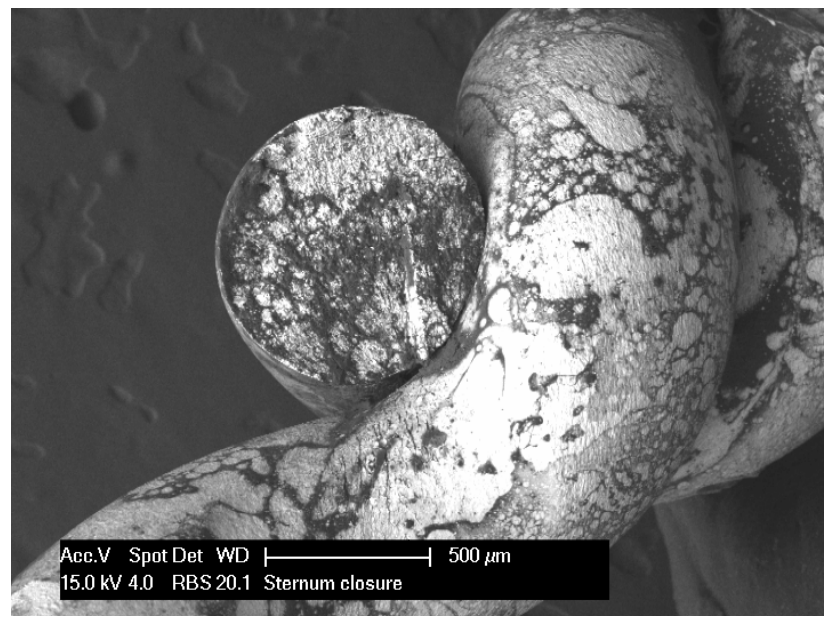

(a)

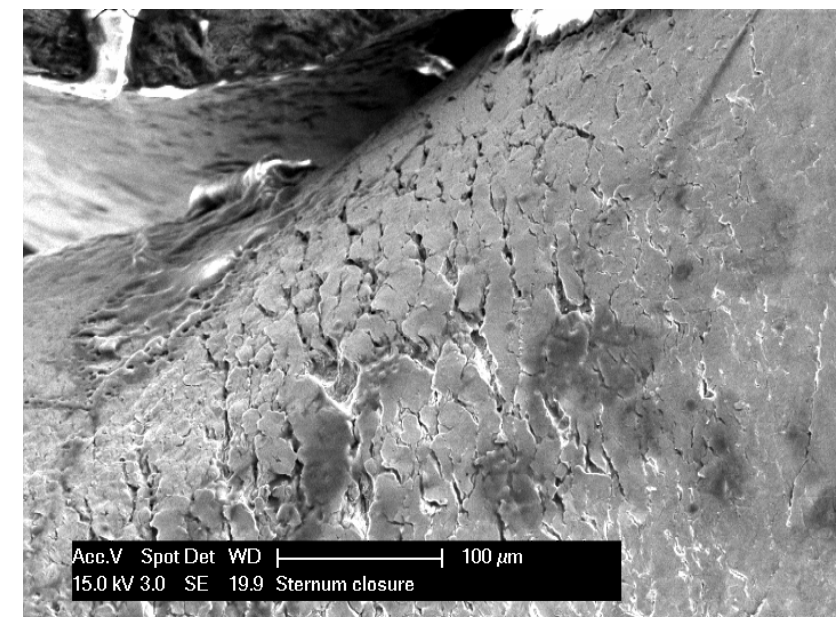

(b)

Figure 1. SEM micrograph of a broken sternum closure wire, retrieved from a patient about five month after surgery. (a) Overview; (b) detail of the non broken part showing micro cracks.

in-vivo broken wire that was removed from the patient, about five month after surgery. The fracture surface occurs at the first winding of the twisted area, because the loads are highest at that location and full damage due to the plastic deformation during twisting is present. The adjacent counterpart shows surface cracks, indicating that also this part of material has been loaded close to its limit. The dark "netlike pattern" in Figure 1(a) is due to remaining organic material that was still resident, even after ultrasonic cleaning. The remaining organic material on the fracture surface is consistent to in vivo fracture.

Moreover, the flexural stiffness and hardness of the steel wire will cause inhomogeneous load distribution on the sternum, after closing and tightening. Locations with high pressure on the sternum bone may cause bone cutting and local bone degeneration. A possible solution for these problems may be to close the sternum with polymer cables. Such cables may be less sensitive to fatigue and they are extremely flexible, thus a very homogeneous load distribution on the sternum may be expected. Considering the occurring loads, it is clear that the tensile strength of the polymer cable must about equalize the strength of the steel wire. Cables made from gel-spun UHMWPE do indeed offer that high tensile strength. Moreover, gel-spun UHMWPE fibers are very resistant to fatigue. Dyneema Purity ${ }^{\circledR}$ was chosen for the present investigation. The material has already been implanted successfully in humans [4] and animals [5]. Dyneema Purity ${ }^{\circledR}$ has quickly become the "gold standard" for rotator cuff repair in human shoulders. More information about the gel-spun Dyneema ${ }^{\circledR}$ fibres is found in other publications [6,7]. Dyneema Purity ${ }^{\circledR}$ is a specially produced grade with extreme purity, thus making it suitable as an implant material. Section 2 describes the investigated materials and the experiments and results. The results are discussed in Section 3, and some conclusions are also presented in Section 3.

\section{Materials and Experiments}

Commercial steel wires are chosen as a representative of a state of the art sternum closure technique. Ethicon surgical steel M649C monofilaments were chosen. The measured thickness was about $1 \mathrm{~mm}$. Cables made of Dyneema Purity ${ }^{\circledR}$ (registered trademark of Royal DSM N.V.), further denoted as UHMWPE cables, were chosen as a representative of the polymer solution. These UHMWPE cables are by far the strongest biocompatible polymer implant material that is available. The cables were braided from 16 yarns of 165 dtex (linear density is 16.5 grams per km) Dyneema Purity ${ }^{\circledR}$ UG material. Figure 2 is a picture of both materials. The dimensions are comparable. The diameters are about $1 \mathrm{~mm}$.

Testing of both options is done by laying them around a pair of aluminium blocks that can slide away from each other. The blocks can be loaded in tension by a pin in a hole that is present in each block. Figure 3 shows pairs of blocks surrounded by a steel wire and an UHMWPE cable. This pair of blocks simulates the split sternum in such a way that it is possible to measure the response to mechanical loading of the wires and cables and their connection technique.

Quasi-static tensile tests are performed by mounting the blocks in a Zwick/Roell 1474 tensile testing machine and subjecting them to a separation displacement. The displacement rate was $10 \mathrm{~mm} /$ minute. Forces and displacements are measured during the tests. 


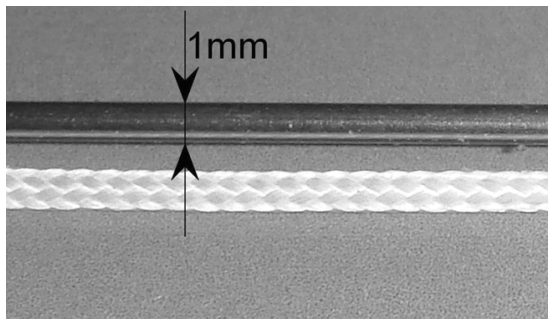

Figure 2. Photo of a steel wire and a cable made with Dyneema Purity ${ }^{\circledR}$ for sternum closure.

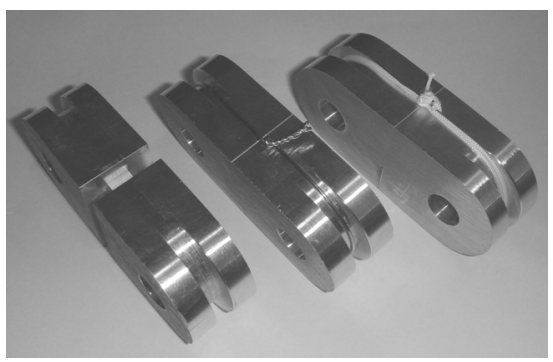

Figure 3. Pairs of blocks; left, a pair of blocks in open condition; middle fixated with steel wire; right, fixated with a cable made with Dyneema Purity ${ }^{\circledR}$.

The connection of the steel wires was made by one experienced surgeon, using the state of the art twisting procedure. The connection of the UHMWPE cables was done by knotting. The knots were tensioned with a predetermined force that was also provided by the tensile testing machine. Two knotting procedures were investigated.

1) A knot based on a racking hitch, allowing easy tensioning. The knot is found in [8,9], The two cable ends are passed through the racking hitch and closed with a half-hitch and tightened with $360 \mathrm{~N}$, followed by two square knot and tightening again with $400 \mathrm{~N}$. This will further be denoted as "stabilized racking hitch"

2) Surgeons knot tightened with $360 \mathrm{~N}$, additionally secured with two square knots tightening again with $400 \mathrm{~N}$. The surgical knot was also made on a double wire, in order to obtain a comparable situation.

The knots that showed the best behaviour were adopted for further testing under fatigue loads. Figures 4 and 5 illustrate both knots.

Fatigue testing is done at two load levels. The pair of blocks is uploaded to $350 \mathrm{~N}$ and subsequently unloaded to $35 \mathrm{~N}$ and further cycled between $35 \mathrm{~N}$ and $350 \mathrm{~N}$ for low load level cyclic fatigue tests. Additional high load level cyclic fatigue tests were performed between $45 \mathrm{~N}$ and $450 N$. Again the load and displacement was continuously recorded. The fatigue tests are performed in a Zwick/Roell Z010 tensile testing machine. The maximum displacement rate in the fatigue tests was $25 \mathrm{~mm} /$ minute.
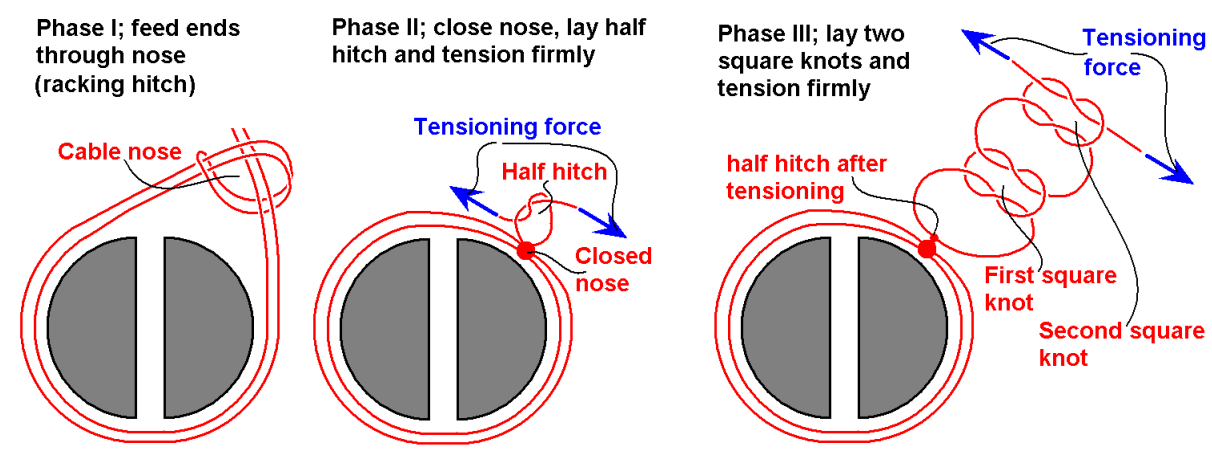

Figure 4. Schematic illustration of the "stabilized racking hitch" knot with security knots.
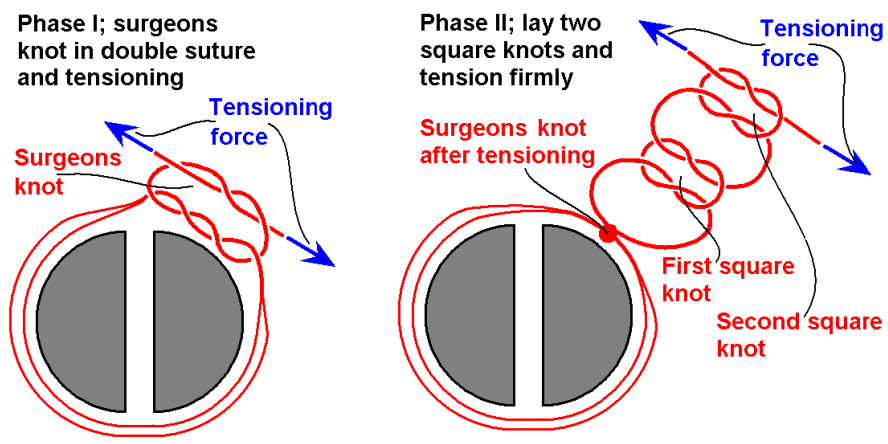

Figure 5. Schematic illustration of surgeons knot with two square knots. 
Figure 6 shows a load displacement diagram of both knots in a quasi static tensile test. It indicates that the stabilized racking hitch provides the best connection. Moreover, this knot is more practical to make and it is somewhat smaller. Therefore, this is the knot that is chosen for further investigations.

Figure 7 compares the load displacement diagram of the metal wire and the stabilized racking hitch in a quasi static tensile test. Some interesting differences can be observed:

1) The maximum load level reached with the UHMWPE solution is larger than that reached with steel wire.

2) The maximum load of the steel wire specimens is related to "plastic unwinding" of the wires. The unwinding could be observed during the test. The upper load region of the UHMWPE solution is less steep than the

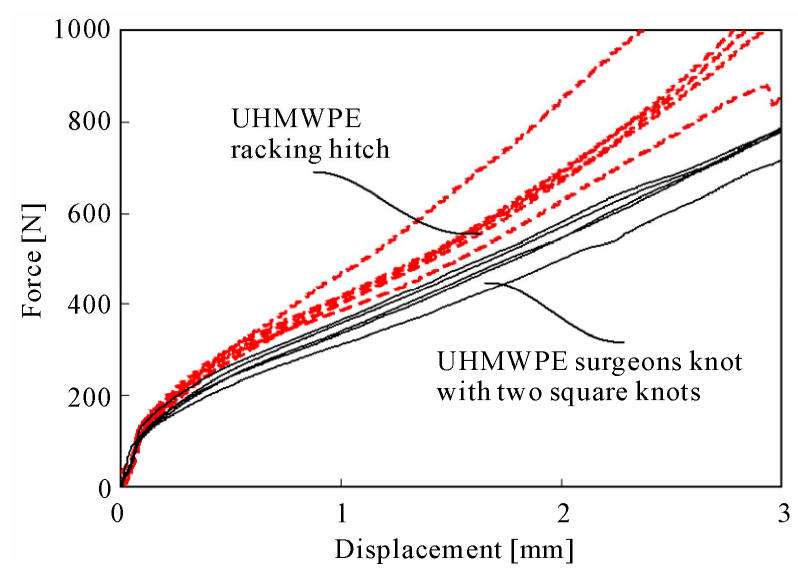

Figure 6. Comparison of the simulated sternum force displacement behavior for the two connections with cables made with Dyneema Purity®.

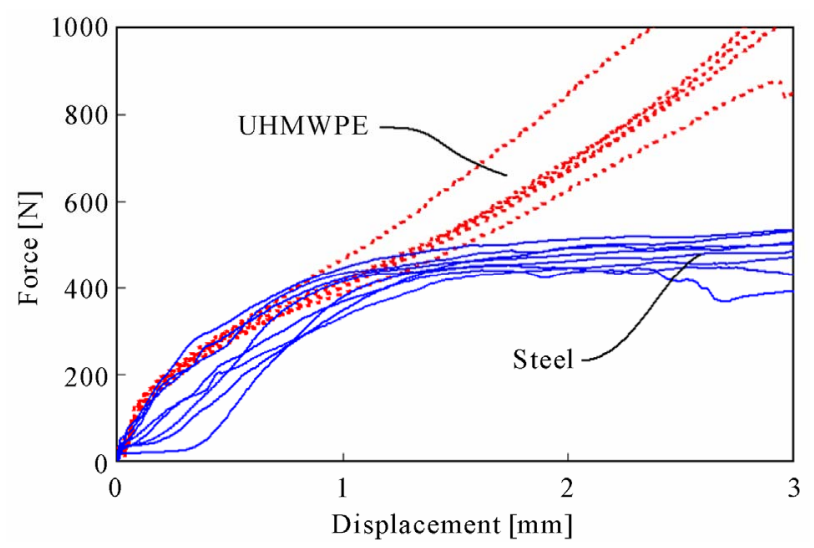

Figure 7. Comparison of the simulated sternum force displacement behavior for the steel wire connection and the connection with the cable made with Dyneema Purity ${ }^{\circledR}$ with the stabilized racking hitch. initial region. This is due to some knot slipping.

3) The nominal behavior at the onset of loading is similar for steel and UHMWPE. However, the steel wire solution shows a more variable load-displacement behavior. About half of the steel wire specimens exhibit a kind of slack.

4) Some sternum opening under load occurs for both solutions. The opening of the UHMWPE specimens shows less scatter, especially at onset of loading, and is on average less than the opening of the steel wire specimens.

Figure 7 gives a good impression of the mechanical behavior of both sternum closure methods. However, it is not yet complete. Quasi-static loading in vivo is only partly relevant. Breathing and coughing represent cyclic loadings that may cause some sternum opening or fracture. Therefore, some tests were performed under cyclic loading. Two maximum load levels were chosen, 350N and $450 \mathrm{~N}$. The minimum load level during cycling was one tenth of the maximum load, so the so called load ratio was 0.1 . The results showed some scatter, so two typical load displacement diagrams are presented per material and load level. The results are presented in the Figures 8-11. The Figures 8 and 9 show typical results of loading at $350 \mathrm{~N}$. Every diagram shows the load displacement excursions for the first 50 cycles, than a set of cycles at cycle numbers $(\mathrm{N})$ of about 1000 and finally a set of cycles at $\mathrm{N}=5000$. The other cycles are not presented, in order to keep the figures readable. Figure 10 shows two tests on the steel wire connection at a maximum force of $450 \mathrm{~N}$. Figure 11 shows one (median) of three tests on UHMWPE cables. The scale of Figures 10 and $\mathbf{1 1}$ is the same as in Figures $\mathbf{8}$ and $\mathbf{9}$. It can be observed by comparing Figures $\mathbf{1 0}$ and $\mathbf{1 1}$ to $\mathbf{8}$ and $\mathbf{9}$, that the displacements are considerably larger at $450 \mathrm{~N}$ than at $350 \mathrm{~N}$. Moreover, the displacements at $450 \mathrm{~N}$ tend to be smaller for the UHMWPE cables than for the steel cables. Figure 11 shows only one of three experiments in order to keep the figure clear. Table 1 presents the data of all cyclic tests.

It can be observed that the "Sternum opening" increases during cycling. This occurs for both materials. However, the increase becomes smaller at high cycle numbers, so the behavior can be called stable. The increase of the opening during cycling at maximum load of $350 \mathrm{~N}$ is on average similar for the steel wires and for the UHMWPE cables. Steel shows somewhat lower opening at the maximum level. UHMWPE shows lower opening at the minimum load level. The displacements at the $450 \mathrm{~N}$ loading were lower for the UHMWPE cables in all cases. Apparently, the UHMWPE cables have more stability at high cyclic load level. 

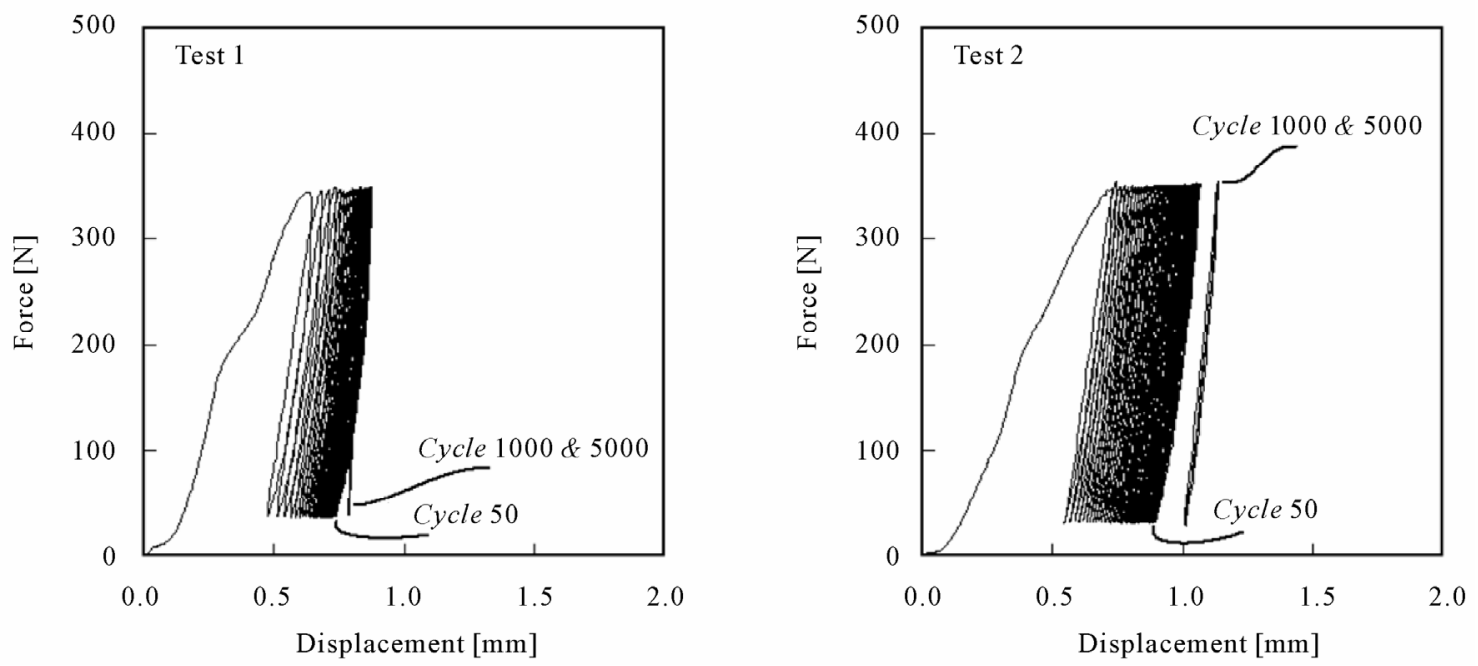

Figure 8. Two measurements of the simulated sternum opening under cyclic loading of a steel wire connection, at a maximum load of $350 \mathrm{~N}$.
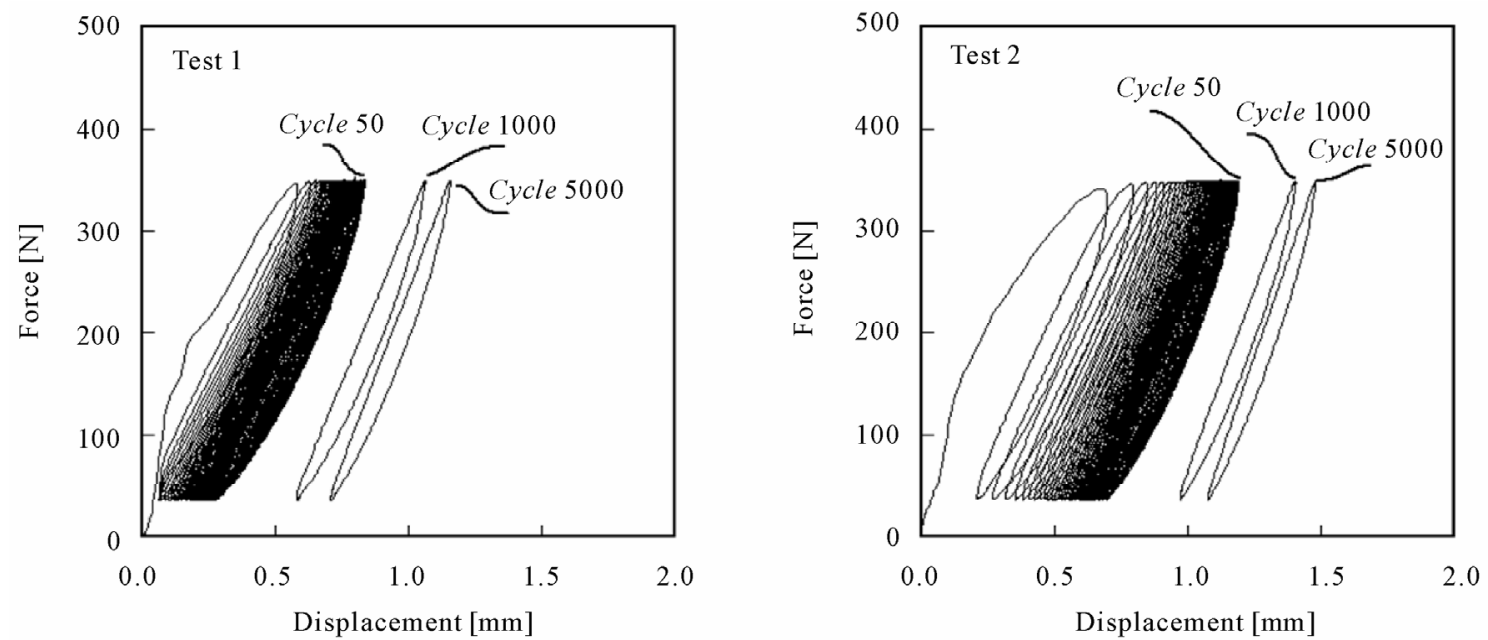

Figure 9. Two measurements of the simulated sternum opening under cyclic loading of an UHMWPE stabilized racking hitch connection, at a maximum load of $350 \mathrm{~N}$.

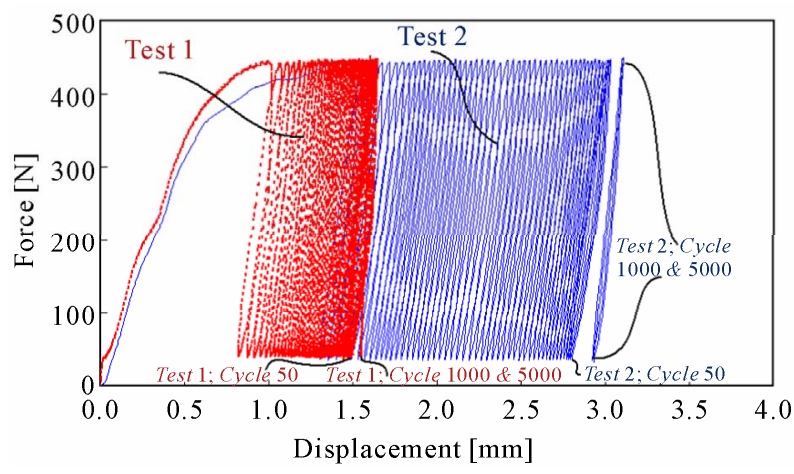

Figure 10. Two measurements of the simulated sternum opening under cyclic loading of a steel wire connection, at a maximum load of $450 \mathrm{~N}$.

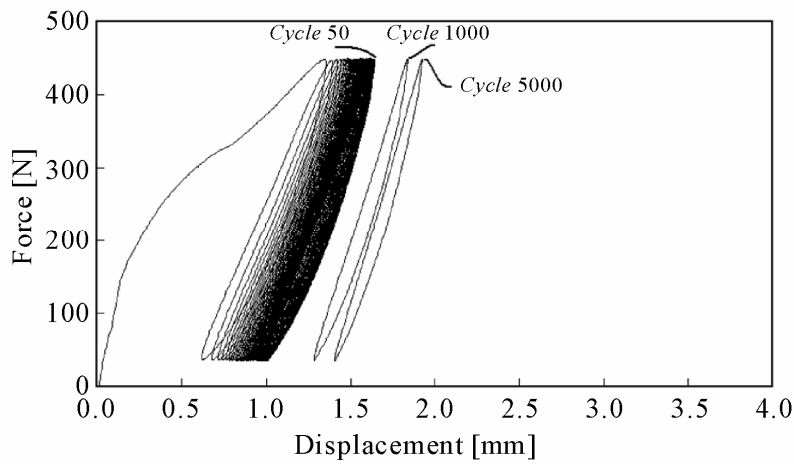

Figure 11. A single (median) measurement of the simulated sternum opening under cyclic loading of a stabilized racking hitch connection, at a maximum load of $450 \mathrm{~N}$. 


\section{Discussion and Conclusions}

The comparison between steel wires and UHMWPE cables in a simulated sternum closure test showed some typical new results. Sternum closure techniques have been investigated earlier on real human cadaveric sternum samples, e.g. by Losanoff et al. [10]. Of course such tests on a real sternum yield the most relevant information regarding the behavior of the total system (sternum plus connection technique). However, the real sternum may be subjected to local indentation due to wire or cable forces. Thus it reacts "soft" and this "softness" may compensate for small displacement effects in the connection device. The present hard metal blocks do not show such compensation effects and the isolated behavior of the connection can be established more accurately. This set up sacrifices the realistic simulation of a complete in-vivo system on behalf of more precise observation of structural behavior in detail. Indeed it is observed that the twisted steel wire connections sometimes show some "slack". This slack is different per connection, in spite of the fact that it can hardly be observed on the specimen and in spite of the fact that they are all made by one trained surgeon in the same way at the same time. The slack may not cause dramatic effects on a real sternum, due to its "softness". However, it will be related to a somewhat decreased average stability. The loading on the different wire connections of the sternum will be different due to different slack. On the other hand, the UHMWPE cables did not show any slack. All UHMWPE cable connections behaved very similar, especially in the first part of the load-displacement diagram. The experimental scatter at higher load and displacement levels are about similar for both materials. However, the maximum load that can be reached with the UHMWPE cable connections is considerably higher. This implies a more fail safe connection. Assume that a sternum is closed with five steel wires, fracture of one wire due to whatever cause will increase the average load on the other wires with $20 \%$. Of course this additional load will not be equally distributed, wires adjacent to the broken ones would even experience more than $20 \%$ load increase. This might cause subsequent failure of other wires. Moreover, possible initial slack of some steel wires would decrease uniform loading and thus increase the problem to some extent. The UHMWPE cable connections show about the double ultimate strength as com-

Table 1. Simulated sternum opening displacements in various cyclic tests.

\begin{tabular}{|c|c|c|c|c|c|c|}
\hline Material-Load & $\begin{array}{l}\text { Minimum Displ. } \\
\text { At } N=50[\mathrm{~mm}]\end{array}$ & $\begin{array}{l}\text { Maximum Displ. } \\
\text { At N = } 50 \text { [mm] }\end{array}$ & $\begin{array}{l}\text { Minimum Displ. } \\
\text { At } \mathrm{N}=1000 \text { [mm] }\end{array}$ & $\begin{array}{l}\text { Maximum Displ. } \\
\text { At N = } 1000 \text { [mm] }\end{array}$ & $\begin{array}{l}\text { Minimum Displ. } \\
\text { At N = } 5000 \text { [mm] }\end{array}$ & $\begin{array}{l}\text { Maximum Displ. } \\
\text { At } \mathrm{N}=5000[\mathrm{~mm}]\end{array}$ \\
\hline Steel-350N & 0.74 & 0.86 & 0.79 & 0.87 & 0.79 & 0.87 \\
\hline , & 0.89 & 1.05 & 1.01 & 1.10 & 1.01 & 1.10 \\
\hline Average ST-350 & 0.87 & 0.96 & 0.90 & 0.99 & 0.90 & 0.99 \\
\hline Steel-450N & 1.50 & 1.62 & 1.54 & 1.65 & 1.55 & 1.65 \\
\hline , & 2.80 & 3.03 & 2.93 & 3.01 & 2.94 & 3.03 \\
\hline Average ST-450 & 2.15 & 2.32 & 2.24 & 2.33 & 2.25 & 2.38 \\
\hline UHMWPE-350N & 0.29 & 0.85 & 0.53 & 1.00 & 0.64 & 1.08 \\
\hline , & 0.28 & 0.83 & 0.58 & 1.06 & 0.71 & 1.16 \\
\hline , & 0.70 & 1.19 & 0.97 & 1.40 & 1.08 & 1.48 \\
\hline Average PE-350 & 0.42 & 0.96 & 0.69 & 1.15 & 0.81 & 1.24 \\
\hline UHMWPE-450N & 0.72 & 1.35 & 0.94 & 1.49 & 1.05 & 1.56 \\
\hline , & 1.00 & 1.64 & 1.28 & 1.84 & 1.41 & 1.93 \\
\hline , & 1.19 & 1.84 & 1.49 & 2.06 & 1.62 & 2.14 \\
\hline Average PE-450 & 0.97 & 1.61 & 1.24 & 1.80 & 1.36 & 1.88 \\
\hline
\end{tabular}


pared to the steel wires and thus will always resist additional loads.

The mechanisms that limit further loading are different for both systems. The twisted steel wires show plastic un-twisting at maximum load. A significant further load increase does not occur if the unwinding takes place. A kind of plastic plateau is observed. Indeed, such a behavior is to be expected, because new twists are exposed to the opening load if previous twists are untwisted. The new twists show similar mechanical behavior as the previous twists, so similar loads will occur. Casha et al. [11] report that steel wires for sternum closure untwist at 20 kg-force. This is equivalent to $200 \mathrm{~N}$. The present results on the blocks yield about $400 \mathrm{~N}$. This is consistent to the value of $200 \mathrm{~N}$ from [11], because the present load is carried about equally by the two locations around the blocks, so the double load is to be expected. It should however be noted that in several cases some opening of the blocks with steel wires occurred at this load. Moreover, due to scatter some specimens never reached this load completely.

The UHMWPE cable connections are limited by knot slipping. Of course the nose cannot slip, but, the half hitch and square knots can slip. Indeed, knots in UHMWPE cables do slip. This helps tensioning and explains the good initial behavior, but it also allows some sternum opening at high loads. Typically knots in UHMWPE cables tend to slip and tighten further under increasing loads, thus the increasing opening under increasing load can be understood. Of course, both plastic untwisting and knot slipping are non reversible processes. Indeed, the cyclic loading curves in the Figures 8-11 indicate that some opening remains after (almost) unloading.

Cyclic loading causes further opening of the simulated sternum model. However, the amount of further opening occurs merely at low cycle numbers. The difference in opening between 1000 cycles and 5000 cycles is very small as compared to the opening that is present at 1000 cycles. Moreover, most of the cyclic opening occurred already at 50 cycles. Assume patients that cough forcefully on average 3 times a minute during one days (quite much). The total number of cycles is almost 5000. Consequently, the number of 5000 load cycles of the present investigation may be considered to be about a realistic number for an upper design limit. Fracture due to cyclic fatigue was not observed in the limited number of the present tests, neither was this targeted for this small number of tests. The cyclic opening of the simulated sternum with both materials might not be expected on forehand. However, cyclic loading of metals that are (partially) loaded above the elastic limit, so where plas- ticity occurs, may result in strain softening. That means that the elastic yield stress decreases during cyclic deformation. In this case, this will be accompanied by increasing displacement. The knots in the UHMWPE cables comprise a complex internal stress system with high normal stresses due to knot tightening and friction shear stresses that provide the holding power of the knot. Cyclic loading will influence the normal stresses in the knot and consequently also influences the related friction stresses. The cyclic variation of the friction stresses will be related to some microscopic displacement under friction in the knot. The total knot slip displacement will of course be in the direction of the average load. Fortunately, also this complex mechanical system in the knot tends to be stable. The further displacements decrease strongly with increasing cycle number.

Summarizing, it can be stated that UHMWPE cables are an attractive alternative for steel wires in sternum closure. The present investigation demonstrated that they provide a strong connection of the sternum parts. They are flexible and highly biocompatible and it may be expected that they will hardly cause local pressure on the sternum bone. Handling in the surgery room is simple and they can be made from commercially provided Dyneema Purity ${ }^{\circledR}$. The present investigation shows that the mechanical behaviour is attractive as compared to state of the art steel wire methods. The initial load displacement behaviour is similar to that of steel wires, but the statistical scatter is lower. The behaviour is more reproducible. The critical load level is much higher than for steel wires, so the UHMWPE cables connections are more redundant than steel and will provide more safety against fracture. The simulated sternum opening behavior under cyclic loading of the UHMWPE cables is similar to that of steel. At high load levels it may even be better.

\section{REFERENCES}

[1] C. C. Shih, C. M. Shih, Y. Y. Su and S. J. Lin, "Potential Risk of Sternal Wires,” European Journal of Cardio-Thoracic Surgery, Vol. 25, No. 5, 2004, pp. 812-818.

[2] C. M. Shih, Y. Y. Su, S. J. Lin and C. C. Shih, "Failure Analysis of Explanted Sternal Wires,” Biomaterials, Vol. 26, No. 14, 2005, pp. 2053-2059. doi:10.1016/j.biomaterials.2004.07.005

[3] K. Schulte, R. Marissen, K. H. Trautmann and H. Nowack, "A Contribution to the Evaluation of Sequence Effects under Variable Amplitude Loading by Applying Defined Predeformations,” AFMMS Conference, Freiburg, 20-24 June 1983, In: G. Sih, E. Sommer and W. Dahl, Eds., Application of Fracture Mechanics to Materials and Structures, 1984, pp. 777-785.

[4] L. van Rhijn, “A New Material for the Engineer's Toolbox: Medical Grade UHMWPE Fibers Provide an Op- 
portunity to Improve Device Performance and Patient Outcomes in MIS,” Bonezone, Winter 2009.

http://medical.dyneema.com/downloadfile.php?file_name =Bonezone_0286082001267369707.pdf

[5] P. M. Montavon and S. Tepic, “Joint Surgery in Canine Hind Limb-Recent Contributions from the University of Zurich,” European Companion Animal Health, 2006. http://www.touchbriefings.com/pdf/2398/tepic.pdf

[6] P. Smith and P. J. Lemstra, "Ultrahigh Strength Polyethylene Filaments by Solution Spinning and Drawing," Journal of Materials Science, Vol. 15, No. 2, 1980, pp. 505-514. doi:10.1007/BF02396802

[7] J. G. H. Bouwmeester, R. Marissen and O. K. Bergsma, “Carbon/Dyneema ${ }^{\circledR}$ Intralaminar Hybrids: New Strategy to Increase Impact Resistance or Decrease Mass of Carbon Fiber Composites," ICAS2008 Conference Anchorage, Alaska, 14-19 September 2008, pp. 1-6.

[8] I. Yonezawa, Y. Arai, T. Tsuji, M. Takahashi and H. Kurosawa, "Atlantoaxial Transarticular Screw Fixation and Posterior Fusion Using Ultra-High-Molecular-Weight
Polyethylene Cable,” Journal of Spinal Disorders \& Techniques, Vol. 18, No. 5, 2005, pp. 392-395. doi:10.1097/01.bsd.0000167127.16576.02

[9] P. G. Rothaug, R. C. Boston, D. W. Richardson and D. M. Nunamaker, "A Comparison of Ultra-High-Molecular Weight Polyethylene Cable and Stainless Steel Wire Using Two Fixation Techniques for Repair of Equine Sesamoid Fractures: An in Vitro Biomechanical Study," Veterinary Surgery, Vol. 31, No. 5, 2002, pp. 445-454. doi:10.1053/jvet.2002.34668

[10] J. E. Losanoff, A. D. Collier, C. C. Wagner-Mann, B. W. Richman, H. Huff, F. H. Hsieh, A. Diaz-Arias and J. W. Jones, "Biomechanical Comparison of Median Sternotomy Closures,” The Annuals of Thoracic Surgery, Vol. 77, 2004, pp. 203-209.

[11] A. R. Casha, L. Yang, P. H. Kay, M. Saleh and G. J. Cooper, "A Biomechanical Study of Median Sternotomy Closure Techniques,” European Journal of Cardio-Thoracic Surgery, Vol. 15, No. 3, 1999, pp. 365-369. doi:10.1016/S1010-7940(99)00014-7 